\title{
DEVELOPMENT OF A LOCAL ANIMAL FEED PRODUCTION LINE USING PROGRAMMING CONTROL SYSTEM
}

\author{
Morad $^{*}$, M. M. ; T. Z. Fouda ${ }^{* *}$; A. A. K. Derbala ${ }^{* * *}$;
}

A. H. EL-Metwalli ${ }^{* * *}$ and E.A.E. Ali ${ }^{* * * * *}$

\begin{abstract}
The present study was carried out to develop programming control system of a locally made animal feed production line. The locally made feed production line consists of three units; feeding unit, milling unit and mixing unit. Performance of the local feed production line was studied under three treatments: three types of control system and three feed rates and evaluated in terms of line productivity specific energy and operational cost. The obtained results can be concluded to the following: Using of programmable control systems for controlling a local feed production line to increase productivity, save energy and cost. It is preferred to use the programmable control system with multimedia interface to control feed production line machines.
\end{abstract}

Keywards: Feed production line, Programmable control systems, Specific energy, operating cost.

\section{INTRODUCTION}

$\mathrm{I}$ $\mathrm{n}$ recent years, most producers focus on the application of quality systems to raise the economic returns and save energy. It is important in the development of production lines to suit the required specifications in the product. So automatic control system serves well private industries related to feed animal are important to increase amount and quality of feed.

Dietrich and Kline (1984) adduced that digital or computer-based process controls optimize process and/or equipment efficiency. Analog

\footnotetext{
*Prof. of Agric. Eng. Fac. of Agric., Zagazig Univ.

** Prof. of Agric. Eng. Fac. of Agric., Tanta Univ.

**** Assoc. Prof. Agric. Eng., Fac. of Agric., Tanta Univ.

${ }^{* * * * * * *}$ Spec of Agri. Eng. Ins. of Agric. Eng. Res, ARC.
} 
controls used earlier were adequate under normal operating conditions. However, they could not respond quickly enough during significant process deviations to make the required adjustments without overshooting. In the past, under these situations experienced operators were needed for manual process control.

Lobe and Swientek (1984) stated that computer-based controls can increase productivity. These systems also increase production, safety, and efficiency in every area of the manufacturing process. The ability to produce the best product at the least cost with employee safety is enhanced

Anon (1985) confirmed that a computer-based process control system is an essential tool of any industry. Even for the small to medium sized industry, handling the flow of process information with an automated system is crucial not only to control the process. But to ensure optimum product quality and productivity. Computerized controls can be used to upgrade existing equipment as well as for new facilities .

Brown (1987) reported that most food plants are not fully automated but are a combination of batch and continuous processing. Broad information should be collected from the operator about the process before automating it through a computer. Most food processes are dynamic and to tune a controller properly, the process must be studied carefully. All features essential to product uniformity should automatically controlled. However, the skills and intuitive reasoning of an experienced operator are very difficult to define and implement within a computer-based system.

Griffin (1990) discussed high-production control system requirements (low work-piece throughput time, low operation-cycle time, low production downtime), servo-based motion technology (precision electric servo motors, feedback transducers, servo amplifiers), and the overall machine design guidelines. In addition, he presented Suggestions for determining the optimum control system cost/benefit balance.

Pedersen et al. (1990) declared that the food industry is facing increasing global competition, regulation, and consumer demands. The need for increased automation in the food industry is due to the 
elimination of extremely repetitive and monotonous tasks. Which resulted in repetitive strain injury to workers.

Stephanopoulos (1993) showed that design of a food process controller would require consideration of the type of unit operations, the range of their conditions. Possible disturbances, manipulations and possible measurements, and problems related to process startup or shutdown.

Swientek (1993) noted that programmable logic controllers PLCs and similar devices are used in the agricultural industry is widespread and growing. Example applications include food processing, building environmental control, grain drying, aquaculture production, and tractor and machinery systems.

Mittal (1997) stated that computerized control systems in the food industry have been recently comprehensively. Industry first needs to identify specific processes to be targeted for automation. Downtime has been drastically reduced with the replacement of electromechanical controls with programmable controllers. they should be familiar with the practical implementation of the control hardware and software. The system operator must know the basic tuning adjustment parameters to tune a controller - gain, reset, and rate.

Linko and Linko (1998) reported that investments in automation, robotics, and advanced control techniques are likely to result in marked savings in costs, increased productivity, improved and more consistent product quality, and increased safety.

Leonik (2000) showed how a PC with Visual Basic (VB) 6 can be used in conjunction with a PLC in a domestic control and monitoring system.

Wang et al. (2009) designed a performance measuring system of agricultural products processing machine for testing the mechanical performance of rice mill and hammer mill. The measuring system was designed based on mechanical devices, took an industrial control computer as host computer, PLC as main control unit. It can measure in real time and display data of transducers of the measuring system. The system can analyze, process, display, output and store sampling data to get related main technical performance parameters of the tested machinery accurately and quickly. By performing experiment al test and 
metrology verification, it is demonstrated that the system runs steadily and every specified control function has been implemented reliably.

Chang et al. (2010) constructed models for creating supervisory control software by a microprocessor-based touch-screen Human-Machine Interface (HMI) and (PLC) standard libraries. This software, in turn, is developed and presented for the Graphical User Interface (GUI) functions used in agriculture wastes reuses process of steam-boiling pretreated to become efficiently produce agricultural biotechnology material and liquid products, such as xylose, and animal feed, thereby providing excellent GUI-based monitoring and control functions. This HMI/GUI approach was presented a very cost-effective technique. In addition, the HMI/GUI operation effectively provides user-friendly and reliable interactions.

Wanghe (2013) designed that a set of unique features of the computer and PLC bus control automatic batching system based on the present situation of application and technical development requirements of production control and management system of a feed enterprise. According to the batching system process and flow control mode and the general structure design of the hardware and software, the design process of variable frequency control PLC batching system hardware setting, parameter setting and system software is described in detail.

Bei et al. (2014) focused in detailed study of the production line control system, the main features and key technologies. According to the actual background of enterprise engineering, production line process proposed general scheme of the automatic control system. The control system has been put into operation, with a friendly interface, stable operation and easy maintenance. The objectives of the work are to:

- Construct an animal feed production line (mill-mixer machine).

- Design a program for running the animal feed production line by control system module.

- Operate the local feed production line using the programmable control system.

- Reduce the operational costs and the consumed energy and raise the work quality. 


\section{MATIRIAL AND METHODES}

The experiments were carried out at private farm in El-qanayat, Sharkia Governorate to manufacture a local feed production line (Auger, Hammer mill and Mixer) and design programmable control system for operating line.

\section{Material:}

\subsection{The tested animal feed:}

Experiments were carried out using animal feed (chick grower ), which was composed of $58.26 \%$ yellow corn, $30.5 \%$ soybean meal (44\% protein), $7.5 \%$ corn gluten $(60 \%), 2.68 \%$ bone meal, $0.35 \%$ salt, $0.15 \%$ limestone, $0.3 \%$ premix (Vit. +Min.), $0.18 \%$ L.lysine and $0.08 \%$ D.L. Methionine.

\subsection{The local feed production line.}

The local feed production line consists of three different units implemented in five stages, as follows in Fig (1).

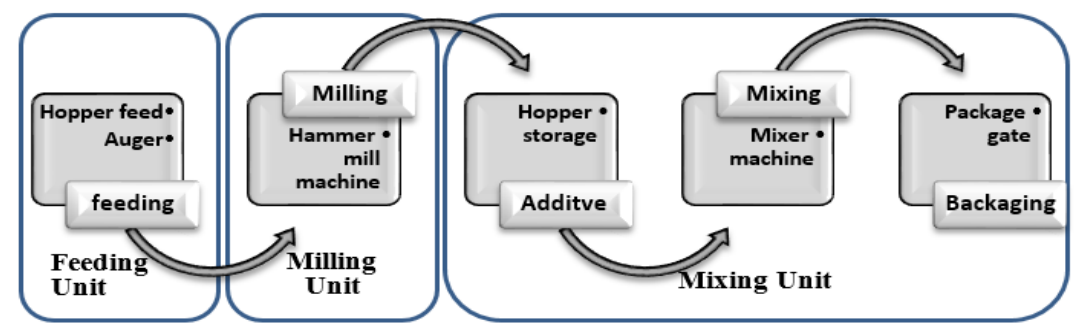

Fig. (1) : The processing stages and units of a local feed production line machine.

- Feeding unit is a screw auger that is used to convey and control feeding rate between main hopper and hammer mill unit. The feeding unit was powered by an electric motor of $3 \mathrm{hp}(2.4 \mathrm{~kW})$.

- Milling unit is a hammer mill machine. The hammer mill consisted of feed hopper, movable knives, screens and frame. The milling unit was powered by an electric motor of $3 \mathrm{hp}(2.4 \mathrm{~kW})$.

- Mixing unit is a vertical mixer. Which consists of feed and mixing screw, electric motor, mixer body, and discharge gate and storage hopper. The mixing unit was powered by an electric motor of $3 \mathrm{hp}$ $(2.4 \mathrm{~kW})$.

Feeding, milling and mixing units have been contacted together taking into account the inclination angle of auger and the possibility of discharging easily into the storage hopper as shown in Fig. (2) and Fig. (3). 


\subsection{The control system}

The control and automation system that control the feed production line was designed based primarily on the electro mechanic panel with programmable control system that was designed using CPU of PC in which the conventional relay-based controller was replaced by control functions.as shown in Fig. (4).

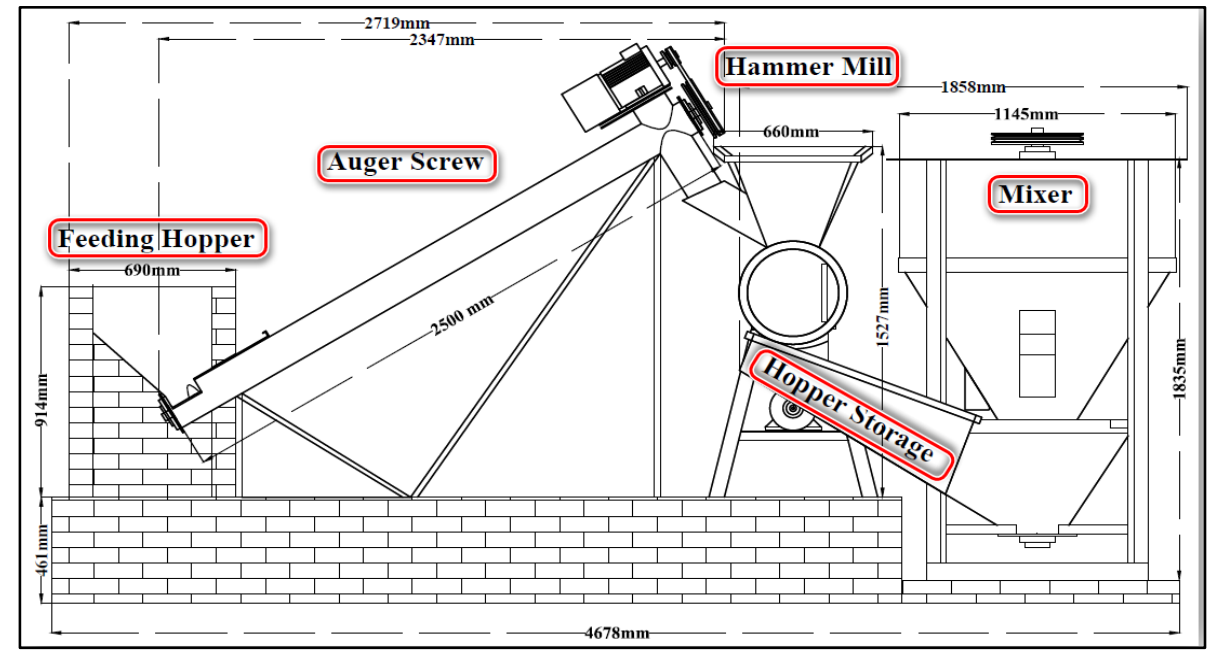

Fig. (2) : The local feed production line.

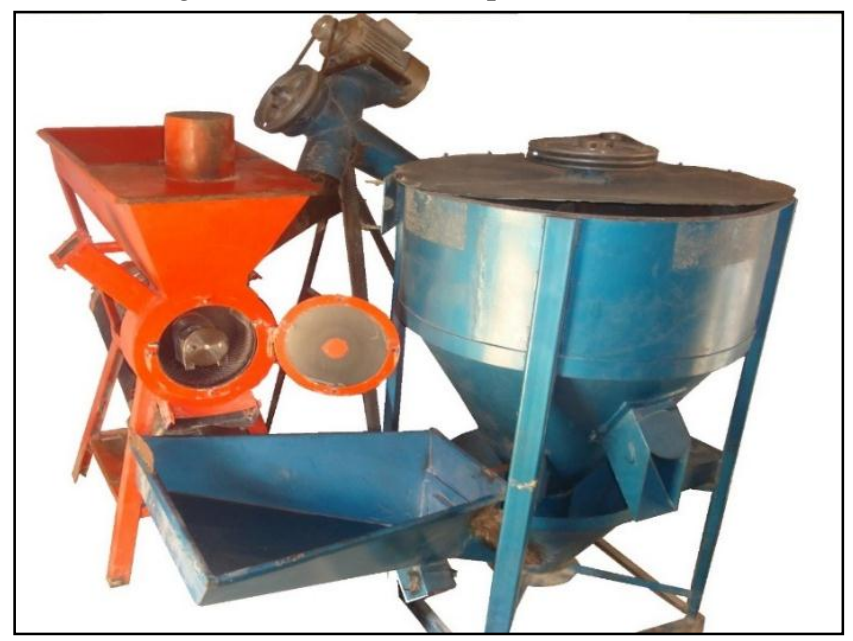

Fig. (3) : A photography of a local feed production line.

Electro mechanic control panel is a metal box contained electromechanical devices (contactors, Electromagnetic relays and Push buttons/switches) to save and control at the electric motor, Electric wires and Indicator lamps. 
Programmable control system consists of personal computer (main power supply, central processing unit CPU), cables (parallel port (LPT) and USB cable A/B), output module (parallel module card) and input modules (operator and input tools). as shown in Fig. (5).

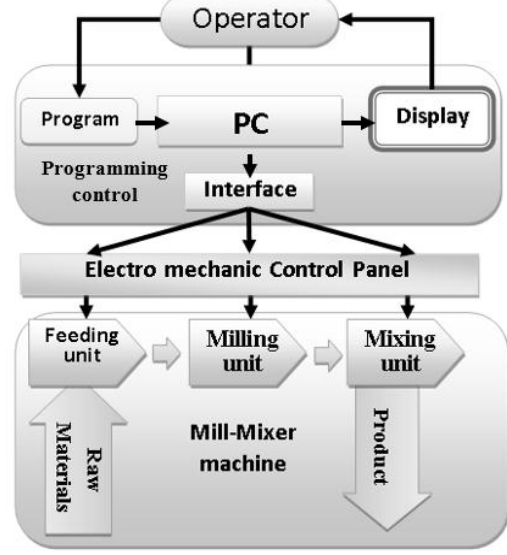

Fig. (4) : A diagram of components

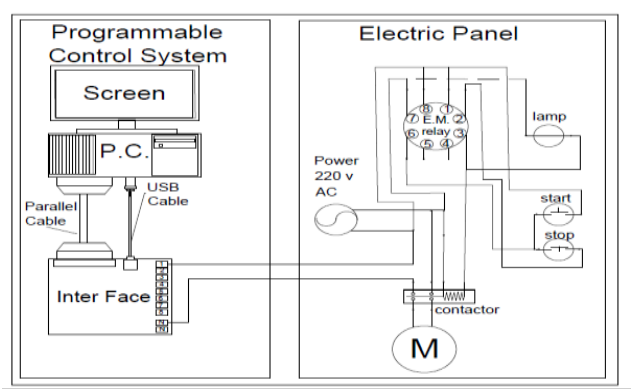

Fig. (5) : Programmable control system

of control and automation system

Control and automation software was written and implemented using MS VB6.0 (sp6).event-driven object-based structured programming language used in the development of data acquisition, control, and measurement applications. Software development in 32-bit environment with the software tools that make it possible for applications running in Windows $\mathrm{XP}$ environment to access system I/O. The program contains one form that some of command button, frames, labels, shapes and tabs which used to work parallel or sequence, as shown in Fig. (6)

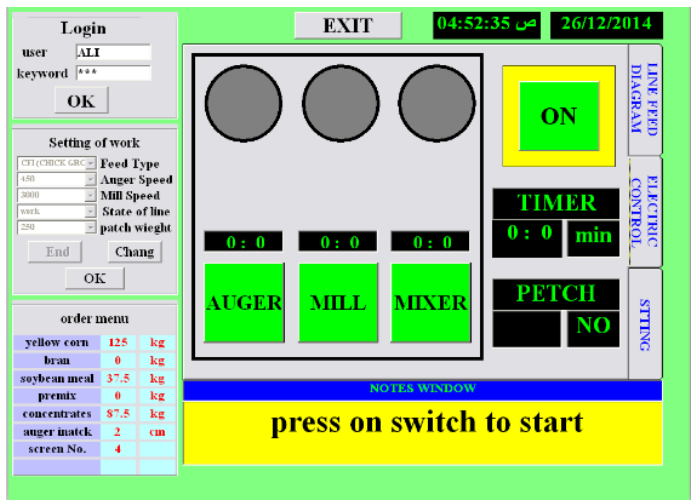

Fig. (6) : Main form of program. 
Fig. (7) shows the schematic of the local feed production line control system.

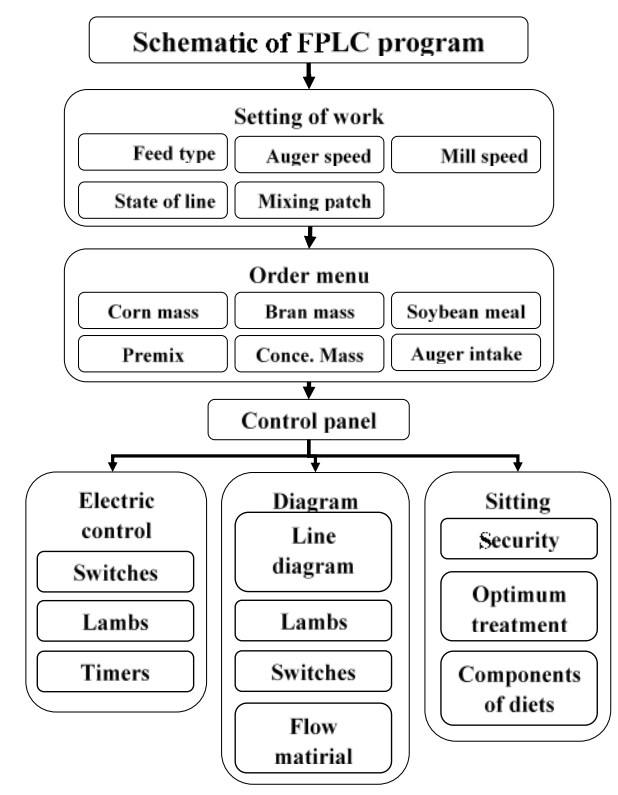

Fig. (7) : Schematic of a local feed production line control system.

\section{Methods:}

All experiments were conducted under constant auger rotational speed of $500 \mathrm{rpm}$ and mixing time of 12 minutes .

\subsection{Experimental conditions:}

- Three operational treatments: A ( auger intake hole area of $25 \mathrm{~cm}^{2}$, rotational mill drum speed of $2000 \mathrm{rpm}$ and screen hole diameter of

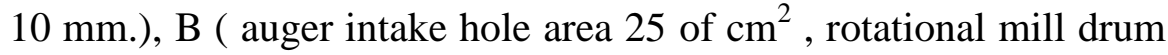
speed of $3000 \mathrm{rpm}$ and screen hole diameter of $12 \mathrm{~mm}$.) and $\mathrm{C}$ (auger intake hole area of $27.5 \mathrm{~cm}^{2}$ and rotational mill drum speed of $3000 \mathrm{rpm}$ and screen hole diameter of $12 \mathrm{~mm}$ ).

- Three types of control system (electromechanical control (EMC) control system with Graphical User Interface (GUI) and control system with multimedia User Interface (MUL)).

- Three feed rates $(370 ; 490$ and $550 \mathrm{~kg} / \mathrm{h})$

\subsection{Performance indicator:}

\section{- Productivity:}

It was estimated using the following equation. 
PROCESS ENGINEERING

$$
\text { Productivity }(\mathrm{Mg} / \mathrm{h})=\frac{\mathrm{W}_{\mathrm{P}}}{\mathrm{T}} \times 3.6
$$

Where:

WP: product mass, $\mathrm{kg}$

$\mathrm{T}$ : productive time, sec

\section{- Required Power :}

The required process power was estimated using the following equation:

$$
\text { Required power, }(\mathbf{k W})=\frac{. I . V \cdot \eta \cdot \cos \theta}{1000}
$$

Where:

I : Line current strength in amperes.

$\mathrm{V} \quad$ : Potential difference Voltage (Being equal to 220v)

$\operatorname{Cos} \theta$ : Power factor (being equal to 0.84).

$\boldsymbol{\eta}$ : Mechanical efficiency assumed (90\%).

- Specific energy (SE):

Machine unit specific energy and total line specific energy were obtained using the following equations (3) and (4), respectively:

$$
\text { machine unit SE, }\left(\frac{\mathrm{kW} . \mathrm{h}}{\mathrm{Mg}}\right)=\frac{\text { The required Power, }(\mathrm{kW})}{\text { Productivity., }\left(\frac{\mathrm{g}}{\mathrm{h}}\right)}
$$

$$
\text { Total line SE }=\text { feed. U.SE + Mill. U.SE + Mix. U.SE }
$$

- Machine hourly cost :

It was determined using the following formula (Awady et al., 1978):

$$
C=\frac{p}{h}\left(\frac{1}{a}+\frac{i}{2}+t+r\right)+(W \cdot e)+\frac{m}{144}
$$

Where:

C : Machine hourly cost, (L.E./h).

$\mathrm{p}$ : Price of machine, ) L.E).

h :Yearly working hours, (h).

a :Life expectancy of the machine, (year).

i :Interest,( rate/year).

$\mathrm{t}$ :Taxes and over heads ratio,(\%).

$\mathrm{r} \quad$ :Repairs and maintenance ratio, $(\%)$.

$\mathrm{W}$ : Power of motor, $(\mathrm{kW})$.

e :Hourly cost,( L.E/Kw.h).

$\mathrm{m}$ :The monthly average wage, (L.E).

144:The monthly average working hours. 


\section{- Operating Cost :}

It is estimated according to the following formula:

$$
\text { Operating cost },\left(\frac{\mathrm{L} . \mathrm{E} .}{\mathrm{Mg}}\right)=\frac{\text { Machine hourly cost }(\mathrm{L} . \mathrm{E} / \mathrm{h})}{\text { Productivity. }(\mathrm{Mg} / \mathrm{h})}
$$

\section{RESULTS AND DISCUSSION}

\section{Effect of control types on line productivity:}

The results revealed the effect of the three types of control system on line productivity (Fig. 7). The results give approximately same values of line productivity for treatments (A) and (B), while under treatment $(C)$ the productivity increased by increasing feed rate from 370 to $550 \mathrm{~kg} / \mathrm{h}$ under the three control systems EMC, GUI and MUL .

The results show that the maximum line productivity of $0.38 \mathrm{Mg} / \mathrm{h}$ with increasing percentage of $15.60 \%$ under treatment (C) with control system (MUL) was observed under the use of feed rate of $550 \mathrm{~kg} / \mathrm{h}$ comparing to control system (EMC). While the minimum line productivity values of 0.22 and $0.22 \mathrm{Mg} / \mathrm{h}$ for treatments (A) and (B) were observed under the use of feed rate $370 \mathrm{~kg} / \mathrm{h}$ and control system (EMC).

The results indicate that the increase of the line productivity noticed with the use of control system (MUL) at all treatments may be due to decline in the time it takes to implement the various stages.

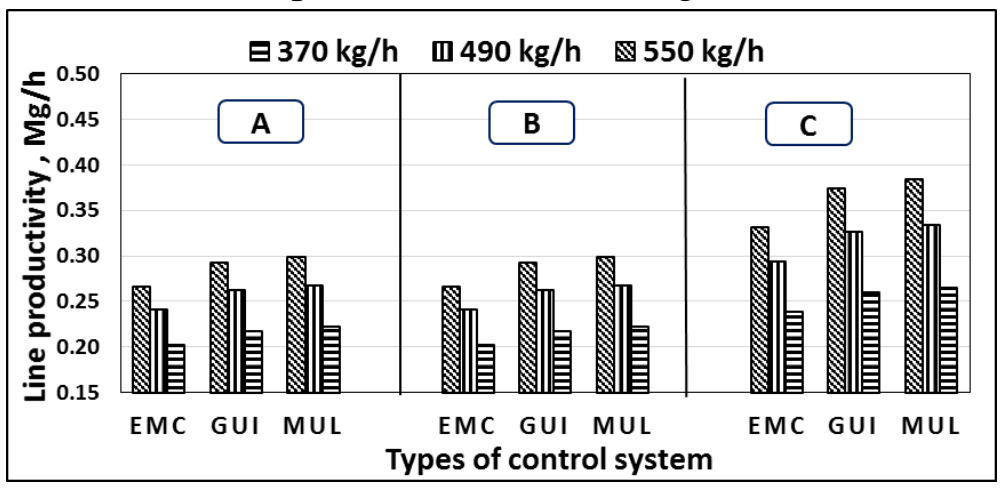

Fig. (7) : Effect of some treatments and control system types on productivity

\section{Effect of control types on line specific energy:}

The results in Fig. 8 explained the effect of the three types of control system has a great impact on line specific energy. The results show that 
the highest line specific energy values were under control system type (EMC) at treatments $\mathrm{A}, \mathrm{B}$ and $\mathrm{C}$. In addition, maximum values of specific energy were under feed rate of 370 at all control system types.

The obtained results show that the maximum value of specific energy $10.2 \mathrm{~kW} . \mathrm{h} / \mathrm{Mg}$ was observed under the use of control system (EMC) and feed rate $370 \mathrm{~kg} / \mathrm{h}$ at treatment (B). While the minimum value was 6.79 $\mathrm{kW} . \mathrm{h} / \mathrm{Mg}$ under the use of control system (MUL) and feed rate $550 \mathrm{~kg} / \mathrm{h}$ at treatment $(\mathrm{C})$.

The specific energy of control system (MUL) was the highest due to increase productivity; that caused a decrease in the total time for the implementation of the batch with low motors run-time.

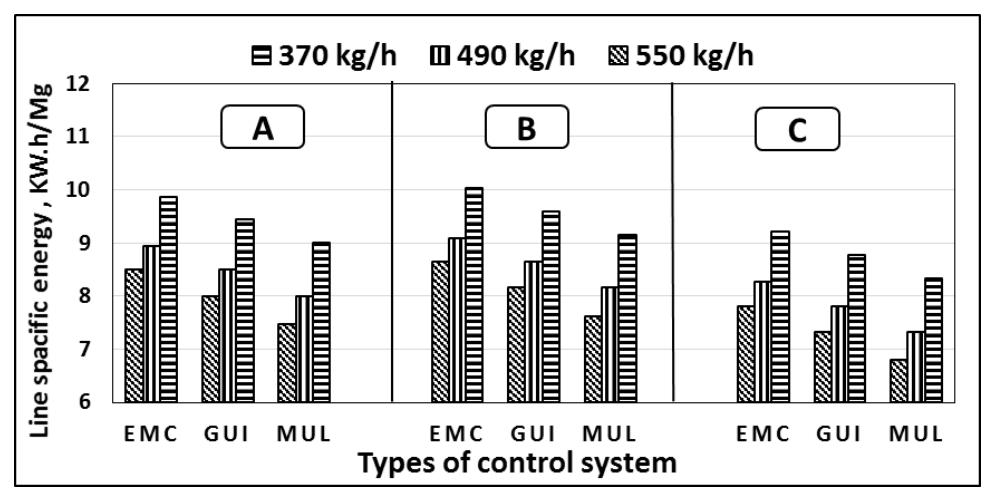

Fig. (8) : Effect of some treatments and control system types on line specific energy.

\section{Effect of control types on line operating cost:}

The results in Fig. 9 show the effect of the three types of control system on line operating cost. The results show that the maximum line operating cost values were under control system type (EMC) at treatments A, B and C. In addition, maximum values of specific energy were under feed rate of 370 at all control system types.

Obtained results show that the maximum value of operating cost was 418 L.E /Mg under the use of control system (EMC) and feed rate $370 \mathrm{~kg} / \mathrm{h}$ at treatment (B). While the minimum value was $233.4 \mathrm{~L} . \mathrm{E} / \mathrm{Mg}$ under the use of control system (MUL) and feed rate $550 \mathrm{~kg} / \mathrm{h}$ at treatment (C).

The results indicate that the operating cost values of control system (MUL) were the lowest at all treatments due to reduction in line required power and increase of line productivity, which in turn reduces operating costs. 


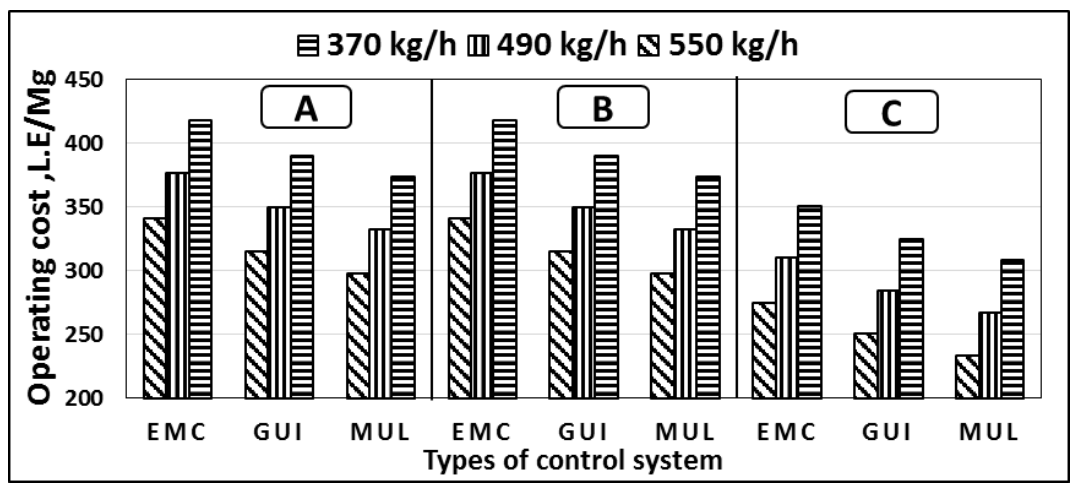

Fig. (9) : Effect of some treatments and control system types on operational cost

\section{CONCLUSION}

This research aimed to develop a local feed production line using programmable control system (computerized-based). The obtained results can be concluded to the following:

- Using of programmable control systems for controlling a local feed production line to increase productivity, save energy and cost.

- It is preferred to use the programmable control system with multimedia interface to control feed production line machines.

\section{REFERENCES}

Anon (1985). Using computers in the meat industry, Meat Process.24 (2):44.

Awady, M. N.(1978). Tractors and farm machinery. Textbook. Agric. Mech. Dept., Faculty of Agric., Ain Shams Univ.: 164-167

Bei, S.; B. Yan and W. Fang (2014). Design and realization of control system of pet feed production line. Feed Industry, (19):2.

Brown, G. (1987). Process control microcomputers in the food industry, Developments in Food preservation-4 (S. Thorne, ed.), Elsevier Appl. Sci , New York, 1987: 35.

Chang, R. F.; C. W. Chang; J.H. Chou and S. Y. Wang (2010). A HMI/GUI control in a steam-pretreated process for agriculture 
wastes reuses. GTI-Green Tech Int. Co. Ltd., Taipei, Taiwan: 168 170.

Dietrich W. and R. Kline (1984). Digital control optimizes spray dryer efficiency, Food Process;45 (3):100.

Griffin, J.M. (1990) Programmable motion control for high production applications Industry Applications Society Annual Meeting, Conference Record of the 1990 IEEE; 7-12 Oct. 1990 , 2 : 1495 1498

Leonik, T. (2000).Home automation basics: practical applications using visual basic .NEW YORK, NY: Delmar learning.

Linko, S. and P. Linko (1998) Developments In Monitoring and Control Of Food Processes. Trans. Chem. E, 76: Part C.

Lobe J. p. and R. J. Swientek (1984) Microcomputer process controllers increase production 30\%. Food process, 45(1):90 .

Mittal, G.S. (1997). Process controls in the food industry: Problems and solutions. In Computerized Control Systems in the Food Industry, 1-11. New York, NY: Dekker Marcel Inc

Pedersen, L. D.; W. W. Rose and H. Redsun (1990) Status and needs of sensors in the food processing industry. Proceedings of food Process Automation, Am. Soc. Agric. Eng. St. Joseph. Michigan, 1990:10.

Stephanopoulos, G. (1993) Chemical Process Control, Prentice Hall, Englewood Cliffs. New Jersey, 1993: 696

Swientek, B. (1993) Placing a premium on real-time management, Prepared Foods, 162(5):74

Wang, Z.J. ; F.P. Xie and S. I. Sun, (2009) Design of performance measuring system for agricultural products processing machine Trans. of the Chinese Soc. Agric. Mach.;40 (3): 93-98 
Wanghe, Z. (2013). Research and Design of Feed Production Line Control System Based on PLC. Science Mosaic, (5):30.

\section{الملخص العربي}

تطوير خط إنتاج علف حيوانى محلى باستخدام نظام تحكم مبرمج

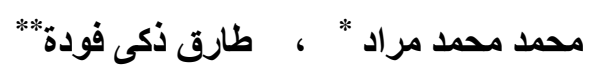

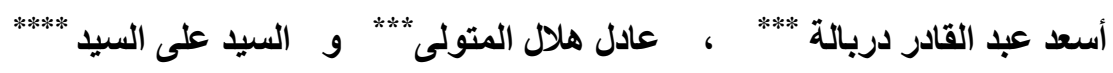

وقد أجريت هذه الدراسة لتطوير نظام التحكم لخط انتاج علف محلى الصنع باستخدام نظام تحكم

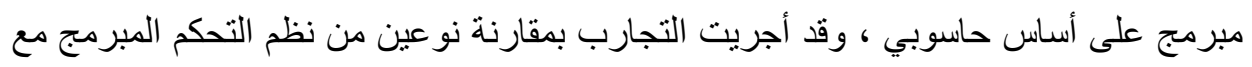

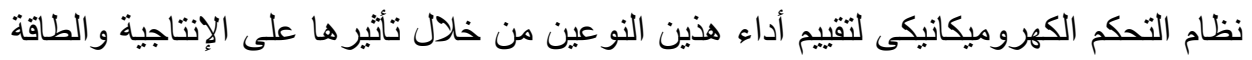

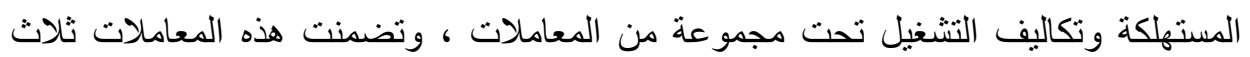

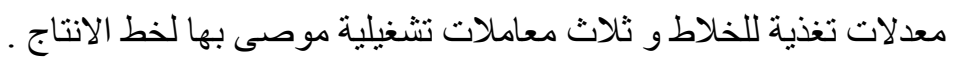
وكانت النتائج المتحصل عليها من التجارب:

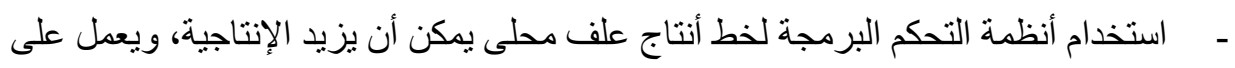

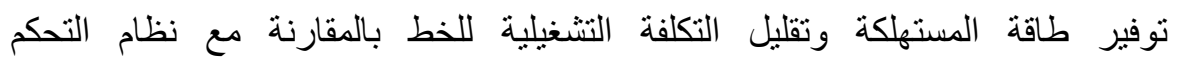
الكهروميكانيكى. - يفضل استخدام أنظمة التحكم القابلة للبرمجة مع واجهة المستخدم ذات الوسائط المتعددة لخط أنتاج العلف المحلى.

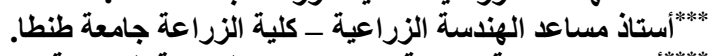

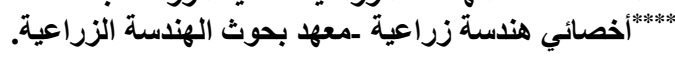

